\title{
RECYCLABILITY OF TECHNOLOGY METALS FROM E-WASTE: CASE STUDY OF In AND Ga RECOVERY FROM MAGNETIC FRACTION
}

\author{
Milisav Ranitovićl ${ }^{*}$, Jovana Đokić ${ }^{2}$, Marija Korać ${ }^{3}$, Nataša Gajićl ${ }^{l}$, Stevan Dimitrijevićl \\ ${ }^{1}$ Innovation Center of Faculty of Technology and Metallurgy in Belgrade Ltd., \\ Karnegijeva 4, 11000 Belgrade, Serbia \\ ${ }^{2}$ Innovation Center of Faculty of Chemistry Ltd., Studentski trg 12-16, \\ 11000 Belgrade, Serbia \\ ${ }^{3}$ University of Belgrade, Faculty of Technology and Metallurgy, Karnegijeva 4, \\ 11000 Belgrade, Serbia
}

Received 13.08.2019

Accepted 01.10.2019

\begin{abstract}
This study presents the results of the theoretical assessment and a preliminary experimental investigation of technology metals (TM) recovery from magnetic fraction obtained after mechanical treatment of waste printed circuit boards (WPCBs). Experimental work included physical and chemical characterization, thermodynamic analysis, and pyrometallurgical tests corresponding to secondary lead, copper, and steel metallurgy. Technology metals recyclability and recovery potential were evaluated with respect to their distribution between metal and slag phase (difficult for recovering) versus the dust phase (easy for recovering). According to obtained results, it was determined that high-temperature processing of magnetic fraction in the electric arc furnace promotes volatilization of the TM and their pre-concentration in the filter as a dust product from which they could be valorized using further hydrometallurgical methods.
\end{abstract}

Keywords: e-waste; magnetic fraction; technology metals; metals distribution; pyrometallurgy.

*Corresponding author: Milisav Ranitović, mranitovic@tmf.bg.ac.rs 


\section{Introduction}

Apart from the metals recovered from electronic waste (e-waste) through conventional recycling processes, such as $\mathrm{Fe}, \mathrm{Cu}, \mathrm{Al}$, and precious metals (PM), e-waste contains a significant amount of special metals, like In, $\mathrm{Ga}$, and $\mathrm{Ge}$. These metals, which are essential for the production and functionality of high-tech devices, are often termed as technology metals (TM), and their recovery may represent another merit to the sustainability management of the e-waste. However, the majority of these metals are part of the complex material matrixes and as such are "hidden" inside specific electronic components. Thus, their recovery requires highly sophisticated recycling technologies, which combine different pyro-hydro-electro metallurgical operations, rather than conventional $\mathrm{Cu}, \mathrm{Fe}$, or $\mathrm{Al}$ recycling methods $[1,2]$. Excluding the several special refining plants that achieve recovery rates of more than $90 \%$, established an industrial practice in the field of e-waste recycling relies mostly on the mechanical operations and as such has remained more or less the same in the past two decades. Some of these technologies are hi-tech, based on different sensor sorting lines for materials separation and recovery [3]. Still, widely applied solutions are technologically much more simplified in which e-waste is shredded before mechanical separation operations [4].

In these processes, magnetic separation represents the early stage operation which follows the shredding of e-waste. However, apart from typical magnetic materials like screws or springs, connectors and casings of the many electronic components such as chips, microprocessors, resistors, transistors, capacitors or diodes are made from ferromagnetic materials. As these electronic components are primary carriers of TM, this magnetic fraction, beside $\mathrm{Fe}$ and $\mathrm{Ni}$, contains a significant amount of metals like $\mathrm{Ag}$, In, $\mathrm{Ga}, \mathrm{Ge}, \mathrm{Ta}$, Ti and so it is attractive for recycling [5].

Nevertheless, the technologies for technology metals recycling from the magnetic fraction of WPCBs are poorly developed. The only small number of recent studies deals with the TM recovery from magnetic materials, and they are generally focused on the recovery of specific metal ( $\mathrm{Ta}, \mathrm{Tl}$ or rare earth elements) from the specific electronic component (transistors or capacitors), usually manually extracted [6, 7]. Other studies investigate recoveries of TM, such as In and Ga, but from LCD monitors, photovoltaic modules and mobile phones or analyze their distribution and potential influences to the metal-slag systems, rather than to investigate methods for their valorization [8-11].

Because of this absence of the recycling technologies, TM from e-waste are being dispersed in different metallurgical sectors. Namely, part of TM bearing components which are attached to the WPCBs, end-up in copper or lead smelters where technology metals are distributed within various products and by-products [12]. However, the vast majority of the TM bearing components, together with magnetic materials, are further processed in steelworks in which recovery and valorization of TM are not of the importance [13]. In this way, both functional and sustainable recovery of materials is not implemented correctly, and leads to contamination of materials streams in recycling and lowers the recoveries of the metal values [14]. Because in current recycling systems, recovery of TM contained in the gas phases is the part of industrial practice, while recovery of those contained in the metal and slag phase is difficult, the fundamental information of the element distribution in smelting processes is of crucial importance [12, $15]$.

Therefore, this paper investigates metallurgical behavior and distribution of TM in different products of the pyrometallurgical processes which correspond to the current 
design of the secondary lead, copper, and steel metallurgy. Thermodynamic calculations were used for the theoretical reconsiderations and prediction of the metal distribution tendencies. Pyrometallurgical experiments were performed in order to determine TM distribution tendencies between metal, oxide (slag) and gas and dust (filter) phases. The results were used to assess if such processing options are capable of producing enriched technology metals pre-concentrate, which is suitable for further processing using conventional hydrometallurgical operations.

\section{Experimental}

\section{Materials}

In presented research, $50 \mathrm{~kg}$ of material, was provided by the local electronic waste recycler. Granulate of magnetic materials was obtained after common mechanical processing of WPCBs extracted from personal computers, which included two-stage shredding in double and single shaft shredders with rotating knives, and magnetic separation using the over belt separator. Samples used in tests were obtained by coning and quartering procedure.

\section{Analytical methods}

In order to investigate the physical and chemical properties of the magnetic fraction, determination of the bulk density, granulometric, material, and chemical composition was performed. The material composition was determined by manual classification and separation of the specific parts and components into the groups, based on their functional and material similarities. Chemical composition was determined by inductively coupled plasma (ICP) using the Thermo Scientific iCAP Q mass and iCAP 6500 Duo optical emission spectrometer. Prior analysis, polymer materials were removed by vacuum pyrolysis $\left(500{ }^{\circ} \mathrm{C}, 0.1 \mathrm{bar}, 1 \mathrm{~h}\right)$ and the pyrolyzed residue was dissolved in the hot aqua regia. The amount of polymers was calculated as the mass difference prior and after pyrolysis, while the solid residue after dissolution represented the total amount of oxides (refractory materials). Chemical analysis of products from laboratory smelting tests was performed by X-ray fluorescence spectrometry (XRF) using the Thermo Scientific ARL Quant'x EDXRF Spectrometer.

\section{Experimental procedure}

Metals distribution tendencies were analyzed from the theoretical and experimental perspectives. Theoretical analysis was based on the thermodynamic calculations performed using the HSC Chemistry software [16]. Experimental investigations were performed by analyzing the composition of each of the phases (metalslag-filter) obtained in smelting tests, which corresponded to the secondary production of lead, copper, and steel. Tests corresponding to the secondary lead metallurgy were performed in the medium frequency induction furnace, reproducing the lead refining stage. Tests corresponding to the direct smelting operations in secondary copper and steel metallurgy were performed in the laboratory electric arc furnace, a system composed of silicon carbide reactor $\left(1.0 \mathrm{dm}^{3}\right)$ located between the tungsten and carbon electrodes. Both systems were coupled with the ventilation hood with the glass fiber filter. In each test, $1.00 \mathrm{~kg}$ of material was processed using the ratio commonly applied in the e-waste recycling industry, a magnetic fraction (10\%) - metal collector (90\%) [17]. Metallic materials with known chemical composition were used as collectors. Results were 
compared to the distribution tendencies obtained during the independent smelting of material, i.e., without the addition of collector.

\section{Results and Discussion}

Results of the physical characterization showed that material bulk density is 1740 $\mathrm{kg} / \mathrm{m}^{3}$, which generally corresponds to the e-waste granulates containing non-metallic materials, both polymer and glass-ceramic, and in which particles larger than $2 \mathrm{~mm}$ are dominant, Table 1.

Table 1. Granulometric composition of the material.

\begin{tabular}{cccccc}
\hline Fraction, $\mathrm{mm}$ & $>4.0$ & $4.0-2.0$ & $2.0-1.0$ & $1.0-0.5$ & $<0.5$ \\
\hline Amount, \% & 49.10 & 29.81 & 17.03 & 2.35 & 1.71 \\
\hline
\end{tabular}

This complex structure of the material was confirmed after analysis of the material composition, by which more than 30 different components and materials have been identified, Figure 1. It was found that components and parts with Fe base (sheets, screws, and springs) dominate in the investigated material, with a total share of 54 wt.\%. Share of the WPCBs was $17 \mathrm{wt} . \%$ while the overall share of the electronic components was 11 wt. $\%$. The residual 18 wt.\% consists of unidentified components and materials such as magnets, wires, plastic-metal composites, fine particles.

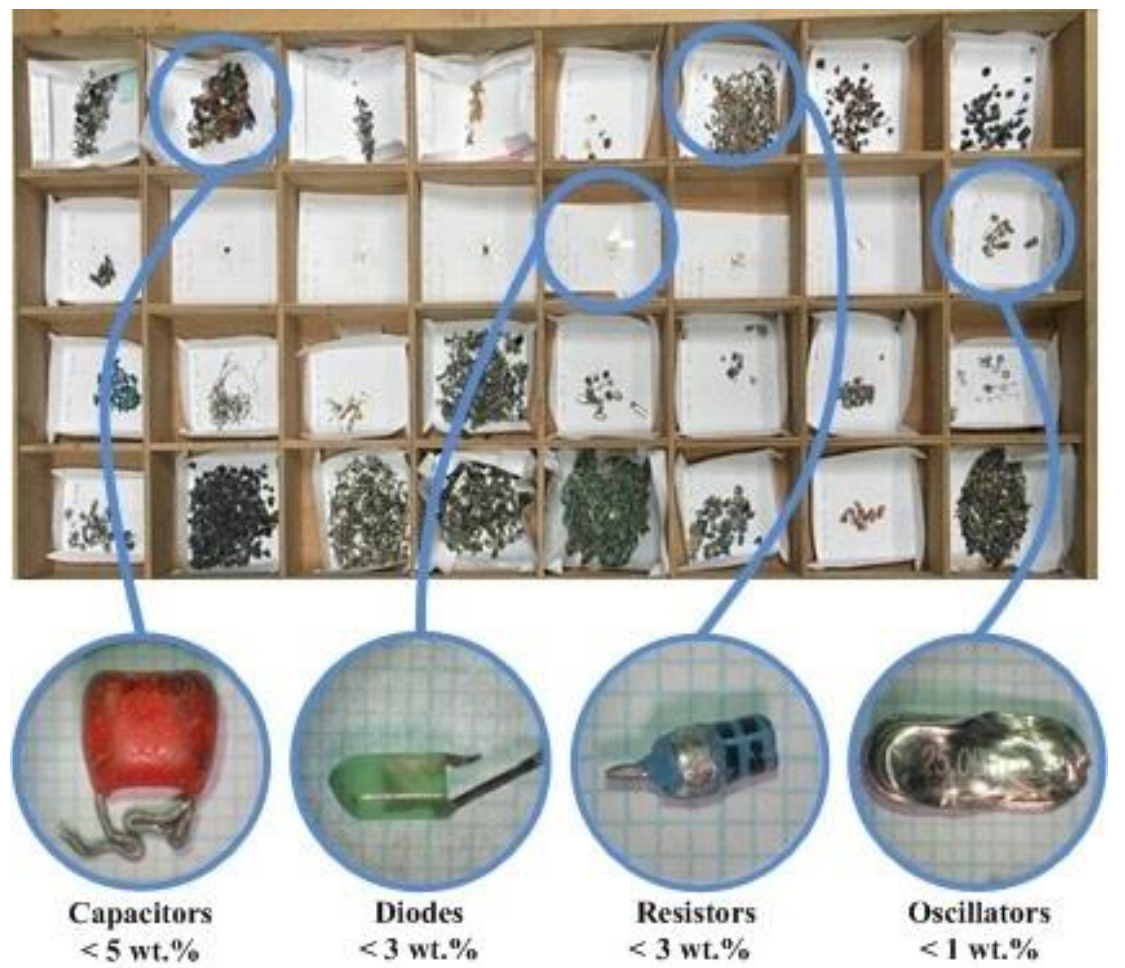

Fig. 1. Classified groups of magnetic fractions, with highlighted electronic components. 
According to the analysis of the chemical composition, as expected, the content of $\mathrm{Fe}$ is dominant (Table 2). However, on contrary to typical magnetic granulates, high content of polymer (5.65 wt.\%) and refractory materials (21.95 wt.\%) was determined, mostly originating from the electronic components, WPCBs, and magnets. Also, it was confirmed that the material contains various TM and PM; this refers to the $\mathrm{Ag}(0.51$ wt.\%), Au (91 ppm) but also to the relatively high content of In (0.20 wt.\%) and Ga (0.16 wt.\%). Since the determined content of Ge (23 ppm) was very low, this metal was not of interest in further investigations.

Table 2. Chemical composition of the magnetic fraction.

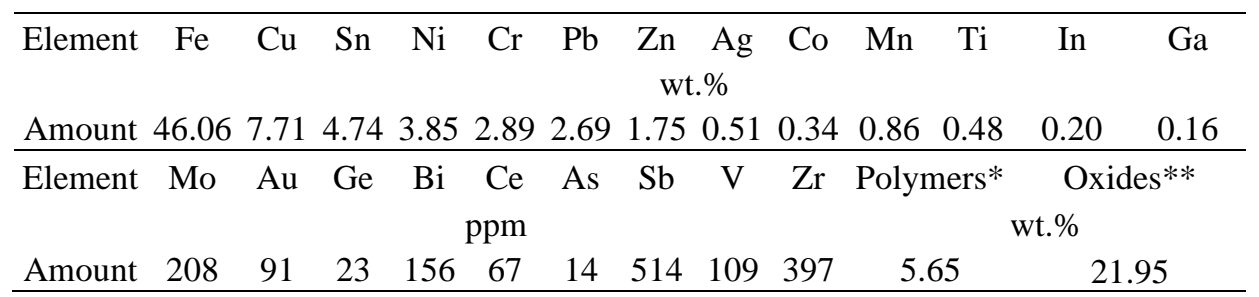

* Plastic and other organics

*** $\mathrm{SiO}_{2}, \mathrm{Al}_{2} \mathrm{O}_{3}, \mathrm{CaO}$ and other refractory materials

Thermodynamic analysis

From the thermodynamic perspective, the distribution of elements during the metallurgical processing may be divided into three groups concerning the value of the equilibrium constant, $K$, [17]:

- Group I $-K<10^{-2}$, elements challenging to oxidize and rather dissolved in molten metal;

- Group II $-K>10^{3}$, elements easily oxidize and mostly found in the slag phase;

- Group III $-10^{-2}<\mathrm{K}<10^{3}$ volatile metals transferred to the filter product phase.

In analyzed cases, excluding the effects of the slag systems, simplified red-ox refining reactions in lead, copper, and steel making industry could be presented as follows:

$$
\begin{aligned}
& \mathrm{PbO}+\mathrm{Me}=\mathrm{Pb}+\mathrm{Me} e_{X} O_{Y(s, l, g)} \\
& \mathrm{Cu}_{2} \mathrm{O}+\mathrm{Me}=\mathrm{Cu}+\mathrm{Me} e_{X} \mathrm{O}_{Y(s, l, g)} \\
& \mathrm{FeO}+\mathrm{Me}=\mathrm{Fe}+\mathrm{Me} e_{X} O_{Y(s, l, g)} \\
& \mathrm{Me}-\text { metal impurity } \\
& \mathrm{X}, \mathrm{Y} \text { - stoichiometric coefficients }
\end{aligned}
$$

For these reactions, values of standard free Gibbs energy $(\Delta \mathrm{G})$ and equilibrium constant $(K)$, are presented in Table 3. 
Table 3. Thermodynamic data of metals in liquid $\mathrm{Pb}, \mathrm{Cu}$, and $\mathrm{Fe}$.

\begin{tabular}{|c|c|c|c|c|c|c|c|c|c|}
\hline & & \multicolumn{2}{|c|}{ In molten $\mathrm{Pb}$} & \multicolumn{4}{|c|}{ In molten $\mathrm{Cu}$} & \multicolumn{2}{|c|}{ In molten Fe } \\
\hline & & $\Delta \mathrm{G}_{873}^{\theta}, \mathrm{kJ}$ & $K$ & & $\Delta \mathrm{G}_{1523}^{\theta}, \mathrm{kJ}$ & $K$ & & $\Delta \mathrm{G}_{1823}^{\theta}, \mathrm{kJ}$ & $K$ \\
\hline $\mathrm{Ag}$ & \multirow{3}{*}{$\begin{array}{l}\text { Metal } \\
\text { phase }\end{array}$} & 147.90 & $6.3210^{-8}$ & \multirow{4}{*}{$\begin{array}{l}\text { Metal } \\
\text { phase }\end{array}$} & 113.84 & $1.6510^{-4}$ & \multirow{9}{*}{$\begin{array}{l}\text { Metal } \\
\text { phase }\end{array}$} & 220.64 & $3.1610^{-7}$ \\
\hline $\mathrm{Au}$ & & 613.30 & $1.3910^{-30}$ & & 564.54 & $1.8610^{-19}$ & & 905.19 & $2.1410^{-27}$ \\
\hline $\mathrm{Cu}$ & & 51.89 & $2.9710^{-3}$ & & - & - & & 141.71 & $6.6810^{-5}$ \\
\hline Co & & -46.44 & $1.8210^{3}$ & & -69.97 & $2.1010^{-3}$ & & 40.80 & $6.2110^{-5}$ \\
\hline Sn & & -134.76 & $3.6310^{6}$ & & -77.319 & $3.69 \cdot 10^{2}$ & & 80.54 & $4.2410^{-3}$ \\
\hline $\mathrm{Ni}$ & & -30.20 & $29.5010^{3}$ & & -45.826 & $3.3210^{3}$ & & 68.16 & $9.8110^{-5}$ \\
\hline $\mathrm{Fe}$ & & -82.24 & $1.0010^{4}$ & & -107.665 & $3.76 \cdot 10^{3}$ & & - & - \\
\hline Mo & & -139.76 & $6.3610^{6}$ & & -224.21 & $2.7910^{7}$ & & 100.35 & $1.1010^{-3}$ \\
\hline $\mathrm{Sb}$ & & -98.98 & $6.5810^{4}$ & & -177.42 & $7.8710^{5}$ & & 148.55 & $4.2010^{-5}$ \\
\hline $\mathrm{Mn}$ & & -102.85 & $1.0210^{5}$ & Slag & -213.888 & $1.27 \cdot 10^{7}$ & & 102.08 & $9.8210^{2}$ \\
\hline $\mathrm{Cr}$ & $\begin{array}{l}\text { Slag } \\
\text { phase }\end{array}$ & -516.95 & $1.4610^{25}$ & phase & -567.96 & $7.2410^{18}$ & Slag & -227.86 & $5.1610^{6}$ \\
\hline $\mathrm{Ti}$ & & -525.76 & $3.9210^{25}$ & & -341.185 & $2.14 \cdot 10^{11}$ & & -325.48 & $3.8810^{9}$ \\
\hline In & & -239.46 & $\begin{array}{c}4.53 \times \\
10^{11}\end{array}$ & & -258.71 & $3.90 \times 10^{8}$ & & 92.68 & $1.86 \times 10^{-2}$ \\
\hline $\mathbf{G a}$ & & -405.09 & $\begin{array}{c}5.24 \times \\
10^{19}\end{array}$ & & -420.53 & $9.21 \times 10^{13}$ & & -67.70 & $9.87 \times 10^{1}$ \\
\hline $\mathrm{Ge}$ & & -149.52 & $1.8910^{7}$ & & -170.76 & $4.6810^{5}$ & $\begin{array}{c}\text { Filter } \\
\text { product }\end{array}$ & 59.28 & $1.7910^{-2}$ \\
\hline $\mathrm{Zn}$ & & -127.74 & $1.6510^{6}$ & Filter & 54.609 & $1.54 \cdot 10^{2}$ & & -15.00 & 2.77 \\
\hline $\mathrm{Pb}$ & & - & - & product & 29.778 & $1.06 \cdot 10^{-1}$ & & 89.90 & $2.2410^{-2}$ \\
\hline
\end{tabular}

By focusing the analysis only to In and $\mathrm{Ga}$, it can be concluded that their distribution tendencies vary concerning the applied metallurgical conditions. According to the values of $K$ in lead and copper metallurgy, both In and Ga may be expected to be oxidized and transferred to the slag phase, $\mathrm{K}>10^{3}$. On the contrary, in steel metallurgy, the value of the $K$ indicates that In and $\mathrm{Ga}$ will be either volatilized, $10^{-2}<\mathrm{K}<10^{3}$, or reduced and collected in molten metal, $\mathrm{K}<10^{-2}$. However, these thermodynamic calculations only describe tendencies of pure metals, which is not in correspondence to with the fact that In and $\mathrm{Ga}$ in addition to their metallic phases are also present as oxides, nitrides, and arsenides.

Accordingly, their distribution between metal, slag, and dust phase is much more complex and depends on the type of compound. Therefore, the relative amount of these compounds as a function of temperature may be analyzed from the perspective of the equilibrium composition for multiphase systems, Figure 2. 


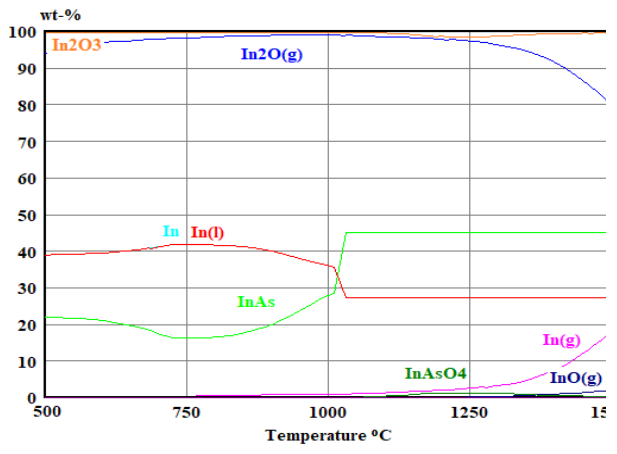

a)

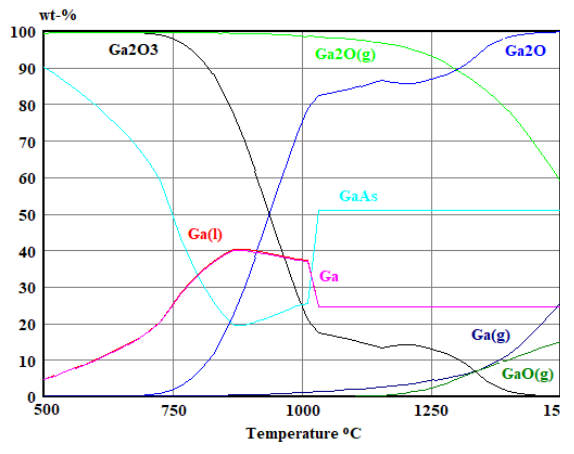

b)

Fig. 2. The distribution of species at equilibrium as a function of temperature: a) In b) $G a$.

As presented in Figure 2, due to their multiphase presence, In and Ga may be expected in all products of the pyrometallurgical processing. In particular, as presented in Figure $2 \mathrm{a}$ ), $\mathrm{In}_{2} \mathrm{O}_{3}$ is stable in the investigated temperature range and therefore will be concentrated in the slag phase. On the contrary, the volatilization of $\operatorname{In}_{2} \mathrm{O}$ may start just below $500{ }^{\circ} \mathrm{C}$. However, this suboxide is relatively unstable and easily oxidizes to the volatile $\mathrm{InO}$ and stable $\mathrm{In}_{2} \mathrm{O}_{3}$, so that only a certain amount may be transferred to the filter phase. Since the transformation of $\mathrm{InAsO}_{4}$ to volatile $\mathrm{InO}$ and In intensifies with temperature increase, on temperature below $1500{ }^{\circ} \mathrm{C}$ only a small amount, less than $20 \%$, could be transferred to the gas phase. S. Similar, volatilization of metallic In could be expected on higher temperatures, above $1200^{\circ} \mathrm{C}$. Analog composition of the multiphase system may be observed for Ga, Figure 2 b), except for the $\mathrm{Ga}_{2} \mathrm{O}_{3}$, which is not stable as $\mathrm{In}_{2} \mathrm{O}_{3}$ and in the temperature region between 750 and $1000{ }^{\circ} \mathrm{C}$ decompose to the volatile $\mathrm{GaO}$ and stable $\mathrm{Ga}_{2} \mathrm{O}$.

\section{Smelting tests}

Experimental investigation of these phenomena was performed through pyrometallurgical laboratory tests. Distribution tendencies of In and Ga, together with other metals, were determined by quantitative and qualitative analysis of each of the phases (metal-slag-filter) obtained in the test which corresponded to the secondary production of lead, copper and steel metallurgy. The composition of inputs, outputs, and process parameters are presented in Table 3. Distribution $(C)$ of metal $\left(M_{i}\right)$ in phase (metal-slag-filter dust) was calculated by eq. (4).

$$
\boldsymbol{C}_{M i}(\text { phase })=\frac{\%_{M i} \text { phase } \times \text { Mass }_{\text {phase }}}{\%_{M i} \times \text { Mass }_{I N P U T}}
$$


Table 3. Composition of inputs, process parameters, and outputs for laboratory smelting tests.

\begin{tabular}{|c|c|c|c|c|c|c|c|}
\hline \multirow{2}{*}{$\begin{array}{l}\text { Metal } \\
\text { collector }\end{array}$} & \multirow{2}{*}{$\begin{array}{l}\text { Time, } \\
\text { Min }\end{array}$} & \multirow{2}{*}{$\begin{array}{c}\text { Temperature, } \\
{ }^{\circ} \mathrm{C}\end{array}$} & \multirow{2}{*}{ Input, $g$} & \multirow{2}{*}{ Output, $g$} & \multicolumn{3}{|c|}{ Output products, $\%$} \\
\hline & & & & & Metal & Slag & Dust \\
\hline $\mathrm{Pb}$ & 60 & 600 & 1000 & 987.20 & 87.80 & $* 12.20$ & $* *_{-}$ \\
\hline $\mathrm{Cu}$ & 20 & $1250-1300$ & 1000 & 994.70 & 65.54 & 28.49 & 5.43 \\
\hline $\mathrm{Fe}$ & 20 & $1550-1600$ & 1000 & 985.45 & 56.42 & 35.94 & 7.64 \\
\hline $\begin{array}{c}\text { No } \\
\text { collector }\end{array}$ & 20 & $1550-1600$ & 1000 & 997.25 & 65.34 & 25.57 & 6.44 \\
\hline
\end{tabular}

*skimmed from the surface of the melt

$* *$ no filtering product

In the first test, the mixture of molten lead and material was constantly stirred and held just above standard lead refining temperature $\left(600^{\circ} \mathrm{C}\right)$ at which lead oxidation and evaporation is prevented. After the 60 minutes, mixing was stopped, and solid particles of the material were skimmed off from the surface of the melt. The chemical composition of the obtained lead bullion is presented in Table 4.

Table 4. Chemical composition of the lead bullion.

\begin{tabular}{cccccccc}
\hline Element & $\mathrm{Pb}$ & $\mathrm{Sn}$ & $\mathrm{Fe}$ & $\mathrm{Zn}$ & $\mathrm{Ag}$ & $\mathrm{Au}$ \\
\hline \multirow{3}{*}{ Amount } & 99.24 & 0.49 & 0.19 & 0.04 & 361 & 7 \\
\hline
\end{tabular}

As presented, in the obtained $\mathrm{Pb}$ bullion a very small amount of the base metals was detected. However, according to the results of quantitative and qualitative analysis, it was calculated that about $68 \%$ of $\mathrm{Ag}$ and $75 \%$ of $\mathrm{Au}$ was collected in $\mathrm{Pb}$ melt. Nevertheless, as the processing temperature is far below volatilization temperatures for most metals, as well as from the melting temperature of slag forming compounds, neither filter products nor typical slag phase was obtained. Furthermore, as the concentration of both In and $\mathrm{Ga}$ were bellow detection limit, no TM content was detected in Pb bullion leading to the conclusion that the majority of TM remains intact inside components skimmed from the $\mathrm{Pb}$ melt.

Distribution of metals, determined under the eq. (4), obtained in the following experiments, is presented in Figure 3. Gold was detected only in metallic phases, while in slag and dust phases content was mostly below the detection limit (1 ppm). Accordingly, over $95 \%$ of Au distribution in each test was attributed to the metallic phase. 


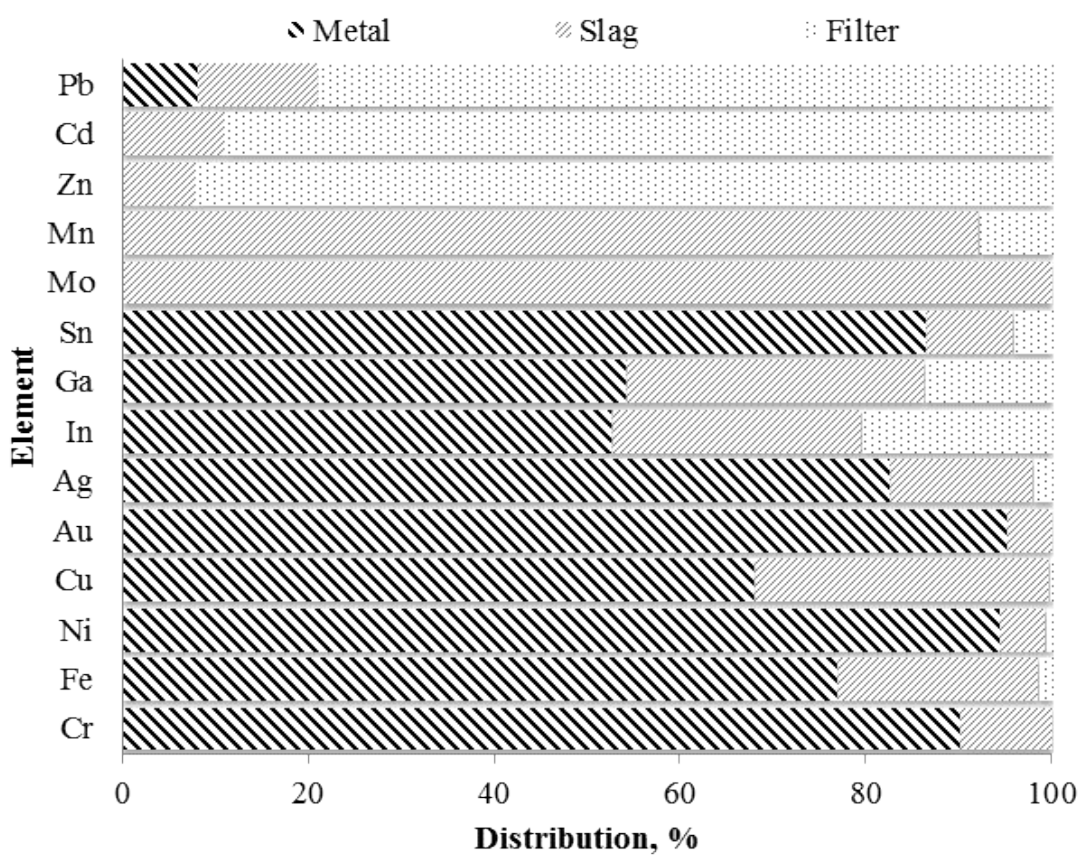

a)

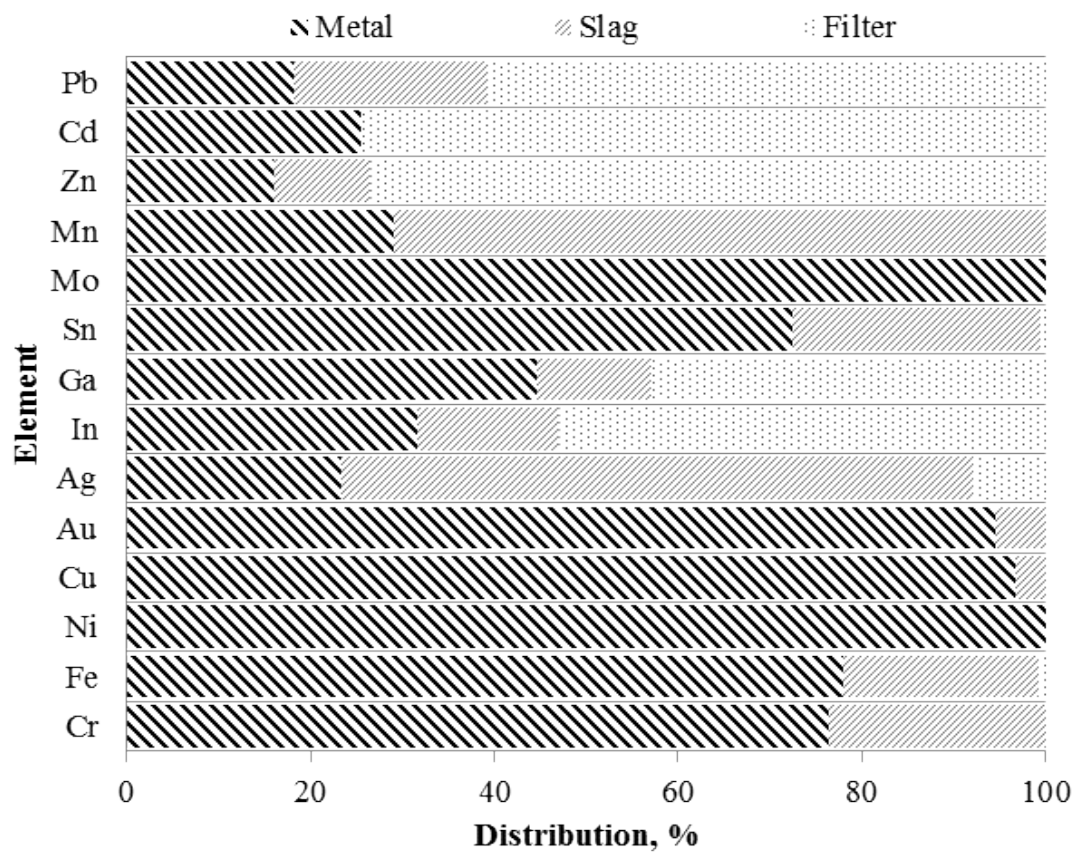

b) 


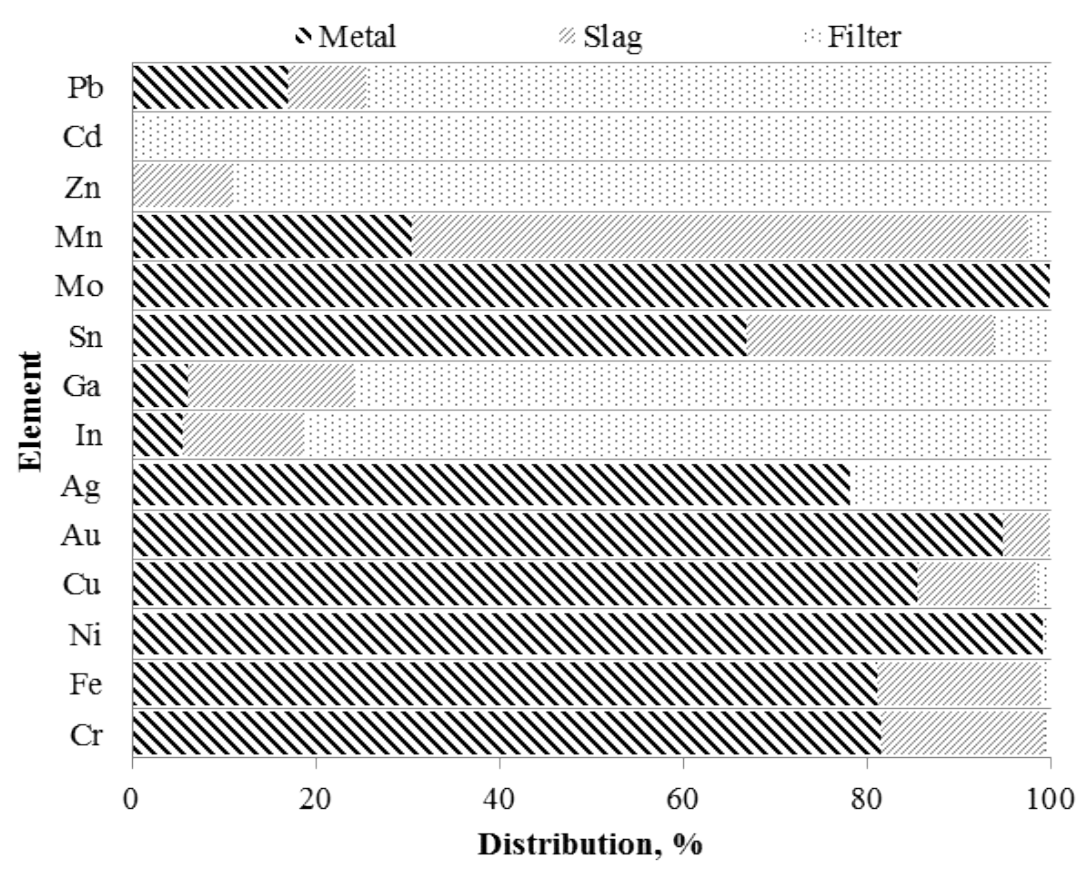

c)

Fig. 3. Distribution of metals in products with a) Cu as a collector, b) Fe as a collector, c) without a metal collector.

As presented, apart from metals like $\mathrm{Sb}, \mathrm{Bi}$, and $\mathrm{Co}$ which in all investigated cases were found to be distributed relatively evenly between all products, or $\mathrm{W}, \mathrm{V}$, and Ti which were almost quantitatively transferred to the slag phase, certain differences of TM distribution tendencies may be observed.

Analyzing the distribution in the test where $\mathrm{Cu}$ was used as a metal collector, Figure 3 a), it was found that In and $\mathrm{Ga}$, are relatively evenly distributed between metal and slag phase, while around $20 \%$ of In and $14 \%$ of Ga were transferred to filter phase. Although valorization of In and Ga may be performed in further copper refining stages, distribution between anodic slime, electrolyte or cement powders, may cause their dissipation.

In the test with $\mathrm{Fe}$ as a metal collector, higher distribution tendencies towards the filter phase were obtained, $52 \%$ and $43 \%$ for In and Ga, respectively. However, knowing that metal contained in slag matrix is complicated to recover and that in ferrous metallurgy recovery of elements distributed in the metal phase is not economically feasible, this distribution is even more unfavorable comparing to the results in which $\mathrm{Cu}$ was used as metal collector and may cause irreversible loss of the majority of TM.

Generally, these results are comparable to those obtained by thermodynamic modeling. Namely, in the system in which Fe was used as collector, distribution of In and $\mathrm{Ga}$ in slag and dust phase corresponds to the value of constant $\mathrm{K}$, which in both cases was on the very border between slag and dust phase. However, in the case of a system in which 
$\mathrm{Cu}$ was used as collector, on the contrary to expected distribution in the slag phase, both In and Ga were relatively evenly distributed in all three phases.

According to the results from the last experiment, presented in Figure $3 \mathrm{c}$ ), it was determined that the absence of the metal collector favors the volatilization of the TM and their transfer towards the dust phase. Comparing the distribution tendencies of the metals to the experiments in which $\mathrm{Cu}$ and $\mathrm{Fe}$ were used as collectors, in the absence of metal collector, over $80 \%$ of In and Ga was transferred to the dust phase, forming the preconcentrate suitable for further processing using conventional hydrometallurgical methods.

\section{Comparison of the recyclability potential}

Comparing the trends in the distribution of elements in the metal, slag, and dust phases observed in the different metallurgical processes in primary production [18], with the distribution tendencies during the pyrometallurgical processing of the magnetic fraction in lead, copper and steel metallurgy, certain deviations can be noted. These differences may be explained by the complex chemical composition of the magnetic fraction, and the introduction of different elements in different amounts not seen in primary production. Higher volatilization rates observed on higher temperatures imply that presence of super alloying and refractory elements causes displacement of liquidus temperatures to higher melting zones and to even more complex interactions in metal, slag, and gas phase, comparing to those already known in the steel, copper, lead or zinc recycling $[12,13,18]$. Accordingly, non-standard high concentrations of these elements result in unpredicted behaviors of metals, causing the lack of selectivity of the conventional pyrometallurgical processes.

\section{Conclusion}

On the contrary to the conventional WEEE recycling processes, in which components like WPCBs are being processed in $\mathrm{Cu}$ or $\mathrm{Pb}$ metallurgy, magnetic materials of WEEE are not correctly managed, and mainly are utilized in ferrous metallurgy. Since the recovery of elements trapped in metal or slag phase is not economically feasible in ferrous metallurgy, most of the technology metals are being irreversibly lost.

Therefore, the development of recycling technologies for comprehensive metals recovery is beneficial both from the perspective of resource efficiency and economic benefits.

Investigation of the TM recyclability from magnetic fraction of mechanically treated WPCBs reviled that conventional pyrometallurgical processes, which correspond to the secondary copper, lead, and steel metallurgy, are not suitable for pre-concentrating of the TM in specific by-products.

According to the results obtained after the introduction of magnetic material in the lead refining process, selective recovery of precious metals could be achieved but not TM. Since the processing is operated far below metals volatilization temperatures, TM pre-concentrating in the metallic phase requires additional mechanical preparation and more improved metals liberation from the components.

Also, high-temperature processing of the magnetic fraction in the presence of the metal collector promotes the dissolution of TM in both metallic and slag phases, which eventually leads to inevitable dissipation between different phases and by-products. However, the absence of metal collectors during the high-temperature processing 
obstructs complex reactions in metal and slag phase, allowing the volatilization of TM and their concentration towards the dust phase. In this way, a specific pre-concentrate of TM, suitable for further hydrometallurgical processing, could be produced.

\section{Acknowledgments}

The presented research was supported by the Ministry of Education, Science and Technological Development, the Republic of Serbia, project "Innovative synergy of byproducts, waste minimization and cleaner production in metallurgy", No.TR34033.

\section{References}

[1] M. Reuter, C. Hudson, A. Van Schaik, K. Heiskanen, C. Meskers, C. Hagelüken, Metal Recycling: Opportunities, Limits, Infrastructure, UNEP, Nairobi, 2013, p. 320.

[2] J. Cui, E. Forssberg: J Hazard Mater 99 (3) (2003) 243-263

[3] N. Hayashi, S. Koyanak, T. Oki: Waste Manage 88 (1) (2019) 337-346

[4] L. Klemettinen, K. Avarmaa, P. Taskinen: ERZMETALL 70(5) (2017) 257-264

[5] K. Mineta, T Okabe: J Phys Chem Solids 66 (2-4) (2005) 318-321

[6] B. Niu, Z. Chen, Z. Xu: J Clean Prod 166 (2017) 512-518

[7] [S. Nagy, L. Bokányi, I. Gombkötő, T. Magyar: Arch Metall Mater 62 (2017) 1161-1166 8. Forsen O, Aromaa J, Lundstrom M: Recycling 2 (4) (2017) 19

[8] J. Yang, T. Retegan, C. Ekberg: Hydrometallurgy 137 (2013) 68-77

[9] Y. Zimmermann, C. Niewersch, M. Lenz, Z. Kül, P. Corvini, A. Schäffer, T. Wintgens: Environ Sci Technol 48 (22) (2014) 13412-13418

[10] B. Flerus, L. Billman, K. Bokelmann, R. Stauber, B. Friedrich: In Proceedings of EMC 2019

[11] 18. K. Nakajima, O. Takeda, T. Miki, T. Nagasaka: Mater Trans50 (3) (2009) 453 460

[12] T. Hiraki, O. Takeda, K. Nakajima, K. Matsubae, S. Nakamura, T. Nagasaka: Sci Technol Adv Mater, 12 (2011) p. 10.

[13] C. Meskers, C. Hagelüken, S. Salhofer, M. Spitzbart: Proceedings of EMC 2009 p. 527

[14] D. Sukhomlinov, K. Avarmaa, O. Virtanen, P. Taskinen, A. Jokilaakso: Min Proc Ext Met Rev (2019) DOI:10.1080/08827508.2019.1634561

[15] Roine A. (2006) HSC Chemistry® v 6.12, Outotec Research Oy Center, Pori, Finland

[16] Ž. Kamberović, M. Ranitović, M. Korać, N. Jovanović, B. Tomović, N. Gajić: J Sust Metal 4 (2) (2018) 251-259

[17] E. Verhoef, G. Dijkema, M.A. Reuter, Process knowledge, system dynamics and metal ecology. - J Ind Ecol 8 (1-2) (2004) 23-43

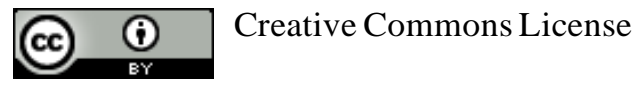

This work is licensed under a Creative Commons Attribution 4.0 International License. 